\title{
Dynamics of Infection in Selected Tissues of White Spot Syndrome Virus-Infected Litopenaeus vannamei
}

\author{
K. Jeena ${ }^{1 *}$, Rahul Krishnan ${ }^{2}$, K. U. Shyam², P. Gireesh Babu ${ }^{3}$, \\ W. S. Lakra ${ }^{4}$, C. S. Purushothaman ${ }^{5}$ and K. Pani Prasad ${ }^{1}$ \\ ${ }^{1}$ Aquatic Environment and Health Management Division, ICAR-Central Institute of Fisheries \\ Education, Mumbai-61, India \\ ${ }^{2}$ Department of Aqualife Medicine, Chonnam National University, Republic of Korea \\ ${ }^{3}$ Fish Genetic and Biotechnology Division, ICAR-Central Institute of Fisheries Education, \\ Mumbai-61, India \\ ${ }^{4}$ ICAR-Central Institute of Fisheries Education, Mumbai-61, India \\ ${ }^{5}$ ICAR-Central Marine Fisheries Research Institute, Kochi-18, India \\ *Corresponding author
}

\section{A B S T R A C T}

White spot syndrome virus (WSSV) remains as the most dreaded pathogen of shrimp aquaculture since its first incidence in China in 1991. WSSV is a double stranded DNA

Keywords

WSSV, virus load, standard curve, Real

Time PCR, $L$.

vannamei

Article Info

Accepted:

22 May 2018

Available Online:

10 June 2018 virus belonging to the genus Whispovirus of family Nimaviridae. It has a wide host range and because of its high virulence it can cause $100 \%$ mortality in a period of 3-10 days. The target tissues of WSSV are of ectodermal and mesodermal origin, including gills, cuticular epithelium etc. In the present study, tissue level dynamics of white spot syndrome virus infection in $P$. vanname $i$ was investigated. For this healthy shrimps were challenged with the virus and a time course quantification of virus load in subcuticular epithelium, gills and pleopods was carried out by Real Time PCR against the generated standard curve, which could detect as minimum as 10 copies of virus in tissue samples. In the examined tissues, the viral load increased as time progressed, however, at different degrees. Compared with gill, viral load was higher in the sub-cuticular epithelium followed by the pleopods. The study provides knowledge regarding the infectivity within the early time periods following infection. This baseline information could potentially contribute in the sensitivity determination during development of diagnostic techniques with enhanced sensitivity which can help to manage the disease to a greater extent.

\section{Introduction}

White spot syndrome virus (WSSV) continues to be the most devastating viral pathogen infecting a wide spectrum of crustaceans and is highly pathogenic to the farmed shrimp Penaeus vannamei, where it is responsible for major economic losses (Walker \& Mohan 2009, Corteel et al., 2012, Shi et al., 2012, Yuan et al., 2016). The first report on the WSSV occurance was in China in 1991 and this was followed by other major aquaculture regions of the world including East and Southeast Asia, the Americas, India, the 
Middle East, and even Europe (Verbruggen et al., 2016). The total economic loss to the aquaculture industry caused by WSSV has been estimated at $\$ 8-\$ 15$ billion since its emergence, increasing by $\$ 1$ billion annually (Lightner, 2012; Stentiford et al., 2012). The portals of WSSV entry into the crustaceans have not yet been clearly studied. Studies have shown differences in sites with respect to the entry. However, the primary sites of WSSV replication in early juvenile Penaeus monodon were found out as subcuticular epithelial cells of the stomach and cells in the gills, in the integument and in connective tissue of the hepatopancreas determined by in situ hybridization (Chang et al., 1995; Di Leonardo et al., 2005). The genome of WSSV has been characterized from three geographical isolates and significant studies have been made in developing various molecular diagnostic methods to detect the virus. However, the information on WSSV infection kinetics in its hosts is limited. In the present study, tissue level dynamics of white spot syndrome virus infection in $P$. vannamei was investigated. This baseline study will be helpful in predicting the sensitivity of different diagnostic tests and in finding the minimal infection level at which the disease could be managed.

\section{Materials and Methods}

\section{Experimental animals}

American white shrimp, Penaeus vannamei were procured from D'souza farm, Naigaon, Maharashtra. Live and healthy shrimps weighing $15 \pm 2 \mathrm{~g}$ were transported in plastic containers with proper aeration and were given dip treatment in $2 \mathrm{ppm}$ potassium permanganate to avoid any infection due to injury and stress. Shrimps were screened for the absence of all the viruses using PCR and were maintained at $281^{\circ} \mathrm{C}$ and salinity of $20 \mathrm{~g}$ L1 with continuous aeration in wet lab of
ICAR-CIFE. Animals were acclimated for $7 \mathrm{~d}$ prior to experimental treatments and fed adlibitum 2 times a day with pelleted feed.

\section{Viral inoculum preparation and WSSV challenge}

White spot syndrome virus inocula were prepared by homogenizing the infected shrimp muscle tissue in phosphate-buffered saline (PBS). The homogenate was centrifuged at $8000 \mathrm{~g}$ for $10 \mathrm{~min}$ and the supernatant collected was filtered using a $0.45 \mu$ PVDF syringe filter. This supernatant was used to inoculate the experimental shrimp. Prior to the injection, the viral load was determined using real-time PCR. In vivo titration revealed that the injection of $5 \times 10^{6}$ copies of virion particles into shrimp resulted in $100 \%$ mortality within 5 days post infection. Animals were injected with the viral inoculum ( $5 \times 10^{6}$ copies) $100 \mu \mathrm{l}$, ventral to the second abdominal segment and were housed individually in tanks.

\section{Tissue collection}

Tissues from three infected shrimps were collected at each time point for the assays. Gill, sub-cuticular epithelium and pleopod were collected from each shrimp at $0,1,3,6$, $12,24,48$ and $72 \mathrm{~h}$ post infection (hpi) and processed for nucleic acid isolation

\section{Isolation of nucleic acids}

Tissues from three animals belonging to the same time point were pooled and DNA was extracted separately from gills, sub-cuticular epithelium and pleopod using the method of Sambrook et al., (2001) with some modifications. The DNA concentration and quality were estimated using a nano volume spectrophotometer and the concentration of DNA were adjusted to $100 \mathrm{ng} / \mu \mathrm{L}$ using nuclease free water. 
Construction of positive control vectors and standards for quantification

The WSSV-VP28 qPCR primers developed by Mendoza-Cano and Sánchez-Paz (2013) were used in the present study. WSSV VP28 fragment containing a $171 \mathrm{bp}$ target amplicon was ligated into the pTZ57R/T vector and transformed into E.coli DH5 $\alpha$.

The plasmid DNA were purified using Miniprep plasmid purification kit (ThermoFisher Scientific, USA) and the plasmid was sent for sequencing at Bioserve Biotechnologies India Pvt. Ltd., (Hyderabad, India) for further confirmation of the clones. The copy number of the target amplicon in the plasmid was estimated and tenfold serial dilution was used as absolute standards for quantification using real-time PCR.

\section{Real-time PCR amplification}

To determine the WSSV load in different tissues at various time points, a SYBR Green based qPCR assay was carried out in LC96 Light cycler (Roche, Germany). The amplifications were performed in a 96-well format with $10 \mu \mathrm{L}$ final volume containing 5 $\mu \mathrm{L}$ of SYBR Green master mix (Takara, Japan), $0.2 \mu \mathrm{L}$ of $(10 \mathrm{pM})$ each forward and reverse primers, $1 \mu \mathrm{L}$ each of DNA dilutions as template.

The reaction was performed in triplicates along with non-template controls to rule out the cross contamination. The thermal profile was $95^{\circ} \mathrm{C}$ for $30 \mathrm{~s}$, followed by 45 cycles of denaturation at $95^{\circ} \mathrm{C}$ for $10 \mathrm{~s}$, annealing at $60^{\circ} \mathrm{C}$ for $10 \mathrm{~s}$ and extension at $72^{\circ} \mathrm{C}$ for $10 \mathrm{~s}$. A series of dilutions of VP28 plasmid were used for generating a standard curve. Analysis of variance (ANOVA) test was used to compare the mean viral copy number at different time points. A Tukey post-hoc test was used to determine significant difference in the viral copy number among tissues at a particular time. All statistical tests were performed using the program SPSS 22.0 (SPSS Inc., Chicago, IL, USA).

\section{Results and Discussion}

\section{Standard curve}

The optimized PCR conditions suggested in the previous studies were applied to develop a standard curve using tenfold serial dilutions of the plasmid DNA. A representative amplification plot generated for the plasmid standard (ranging from $1 \times 10^{10}$ to $1 \times 10^{1}$ copies per reaction) is shown in Fig. 1; each dilution for this experiment was performed in triplicate. The melting curve analysis revealed a single peak for the amplified product with a melting temperature $(\mathrm{Tm})$ of $84.8^{\circ} \mathrm{C}$ (data not shown). A linear correlation $\left(\mathrm{R}^{2}=0.955\right)$ was obtained between threshold cycles (CTs), indicating a detection limit of 10 copies. The slope of $\mathrm{M}=3.39$ is indicative of high reproducibility and precision (Fig. 2).

\section{Viral load in WSSV-infected tissues}

White spot syndrome virus DNA was detected in all the $P$. vannamei tissues by real-time PCR. The tissue level viral load as copy numbers was determined against the generated standard curve (Fig. 2). In all tissues, the viral load increased as time progressed, however, at different degrees. (Fig. 3).

Compared with gill, viral load was higher in the sub-cuticular epithelium followed by the pleopods. In the gill, $2.76 \times 10^{1}$ WSSV DNA copies/ $\mu \mathrm{g}$ of total DNA were detected at $6 \mathrm{hpi}$ and levels continued to increase to $1.85 \times 10^{2}$, $1.5 \times 10^{4}$ and $3.81 \times 10^{6}$ at 12,48 and $72 \mathrm{hpi}$. Compared with gills, WSSV DNA levels in sub-cuticular epithelium showed a tenfold increase at the first sampling $\left(2.97 \times 10^{2}\right.$ WSSV DNA copies $\mu \mathrm{g} / \mathrm{L}$ of total DNA at $12 \mathrm{hpi}$ ). 
Fig.1 Amplification curve showing tenfold serial dilutions of standard samples. Representative plot is depicted. The experiment was run in triplicates

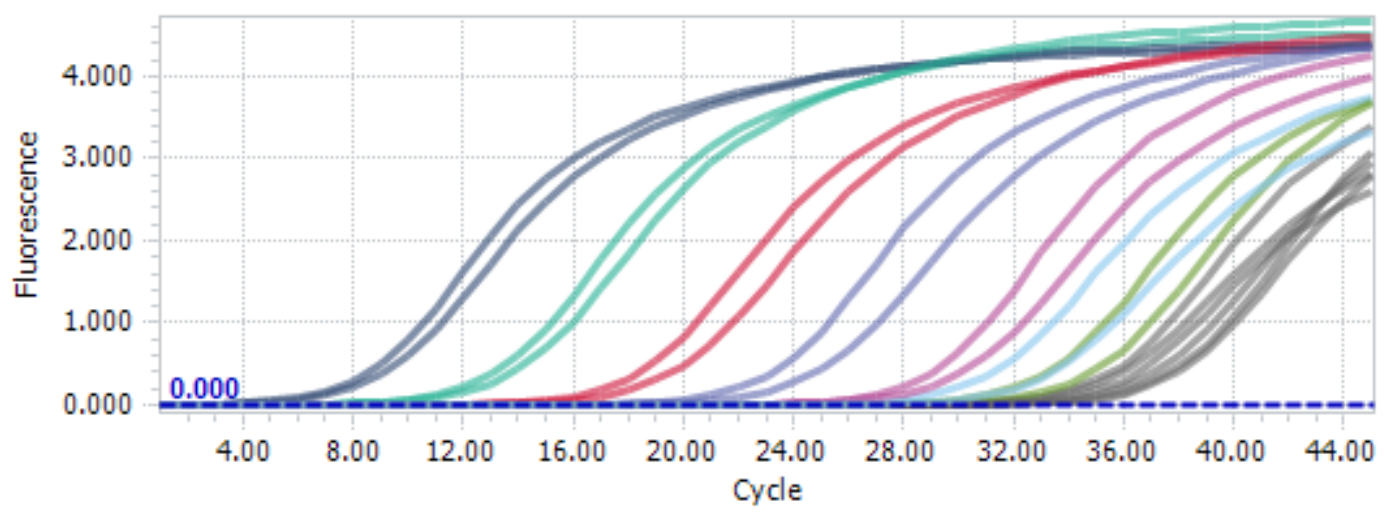

Fig.2 Standard curve of WSSV real-time PCR; Cq, threshold cycles. The correlation coefficient was 0.955 , and slope of the line was 3.39

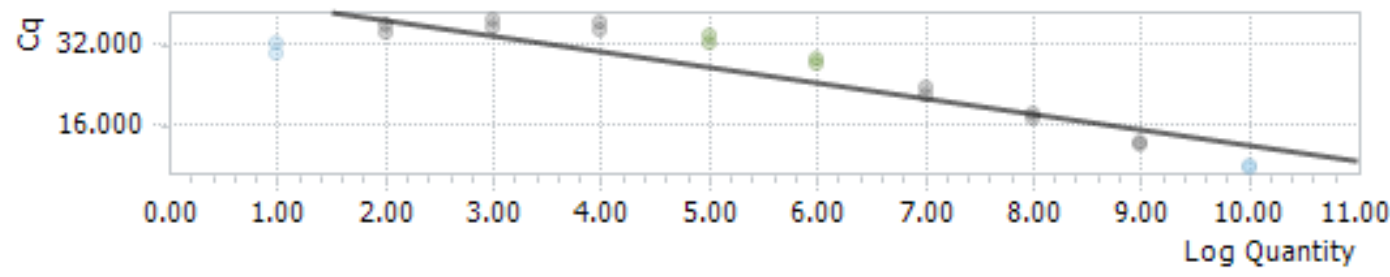

Fig.3 Tissue distribution of WSSV following challenge at different time points. Data represented as mean value of triplicate experiments with standard error. All the values are statistically significant $(\mathrm{P}<0.05)$

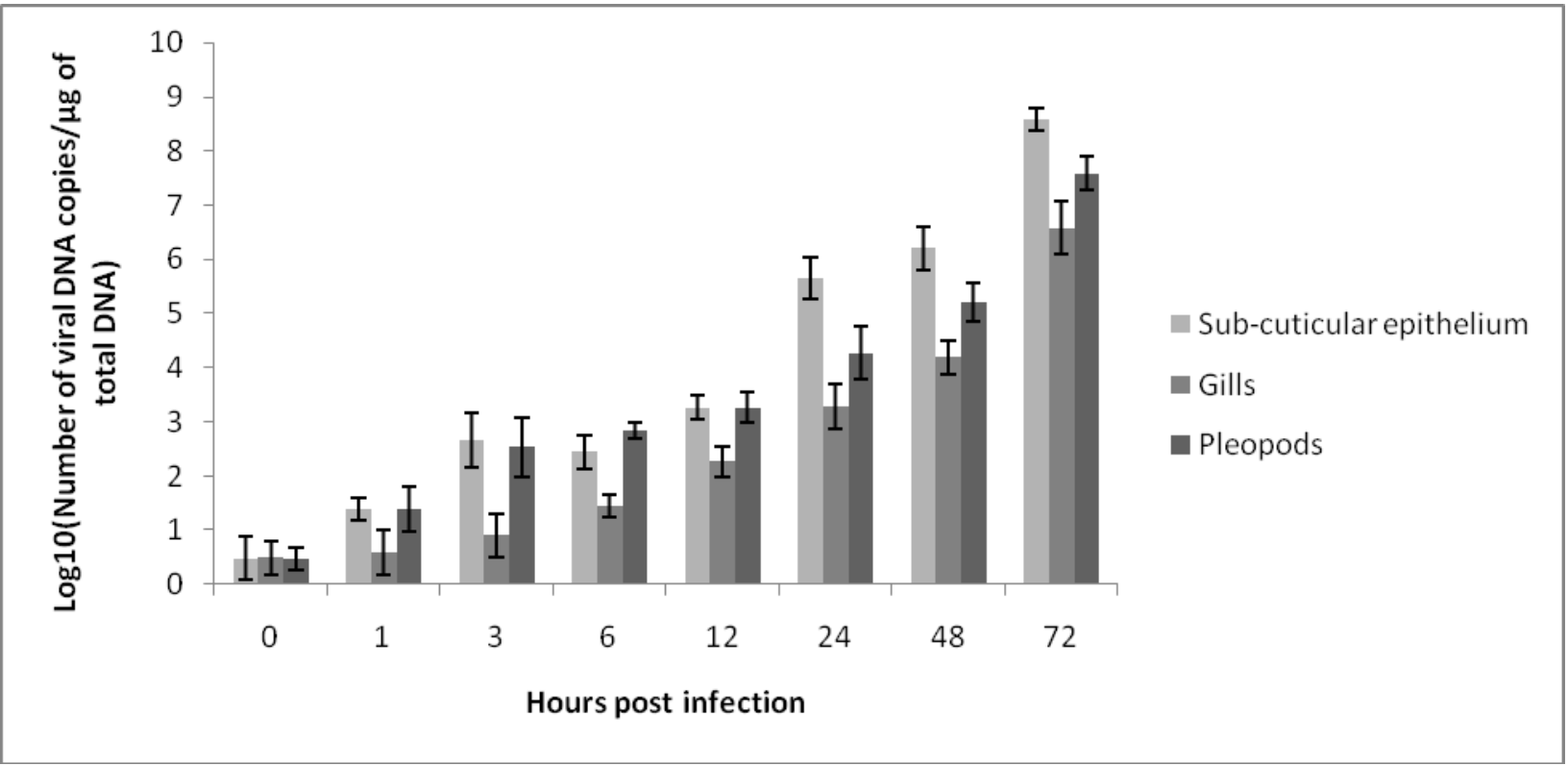


There was no significant difference in the WSSV load between the pleopod and subcuticular epithelium till $12 \mathrm{hpi}$, later it was about tenfold lower at 24 hpi $\left(1.8 \times 10^{4}\right)$, and about 100-fold lower at 48 and $72 \mathrm{hpi}$ $\left(1.5 \times 10^{5}, 3.8 \times 10^{7}\right)$. The viral copy number of tissues at different time intervals, analyzed using one-way analysis of variance (ANOVA), showed a significant difference between tissues at all-time points $(\mathrm{P}<0.001)$. Subsequent pair-wise analysis of WSSV copy number in different tissues at a particular time point.

The present study determined the timedependent viral load in defined tissues of $P$. vannamei experimentally infected with WSSV. A sensitive SYBR green real-time PCR assay developed by Mendoza-Cano and Sánchez-Paz (2013) was adopted. Till date, studies on tissue distribution of WSSV in infected penaeid shrimps are scarce. Durand and Lightner (2002) evaluated the WSSV load in various tissues of different shrimp species using moribund juveniles. Moribund juveniles of $P$. vannamei showed $2.5 \times 10^{9}$, $1.6 \times 10^{9}, 1.2 \times 10^{9}$ and $1.9 \times 10^{8}$ copies of WSSV from haemolymph, pleopod, gills and muscle respectively. Moribund juveniles of $P$. stylirostris and $P$. monodon showed $3 \times 10^{10}$ and $2.1 \times 10^{6}$ WSSV copies in pleopod. This implies that large variations in viral load can be observed between different tissues in the same species and between the same tissues in different shrimp species. A similar trend was observed in the present study showing higher load in the sub cuticular epithelium followed by the pleopod and the gill.

This study demonstrates the viral replication kinetics in each of the tissues during the course of viral replication over a period of time. At 6 hpi, sub-cuticular epithelium and pleopod showed relative high copy number followed by gills (Fig.3). Over time, a rapid increase in viral load is observed in sub- cuticular epithelium. At 24, 48 and 72 hpi, sub-cuticular epithelium showed the highest viral load among all tissues analyzed. According to Escobedo-Bonilla, et al., (2007), the mechanism behind such change in viral distribution is that after primary replication (12 or $18 \mathrm{hpi}$ ), newly produced WSSV would have been released from epithelial cells and crossed the basal membrane to reach the underlying connective tissues.

On the contrary studies of Jeswin et al., (2015) demonstrated that highest viral load followed by WSSV experimental infection was higher in haemocytes at the initial stages and further advanced with a higher copy number in the gills at 24, 36 and 72 hpi in $P$. monodon. WSSV can replicate in all the vital organs of infected penaeid shrimps. The target tissues for WSSV replication includes the epidermis, foregut, gills, antennal gland, hindgut, gonads, lymphoid organ, hematopoietic cells, cells associated with the nervous system, and connective tissue whereas tissues, like hepatopancreas and gut, are refractory to WSSV infection (Zhao et al., 2017).

This study demonstrates the time-dependent WSSV infection kinetics in different tissues and provides knowledge regarding the infectivity within the early time periods following infection. This baseline information could potentially contribute in the sensitivity determination during a diagnostic development and also help to manage the disease to a greater extent.

\section{Acknowledgements}

The authors would like to thank the director ICAR-Central Institute of Fisheries Education for providing the research platform and all the colleagues of Aquatic Environment and Health Management Division of ICAR-CIFE for their technical assistance. 


\section{References}

Chang, P., Lo, C., Wang, Y. and Kou, G., 1996. Identification of white spot syndrome associated baculovirus (WSBV) target organs in the shrimp Penaeus monodon by in situ hybridization. Diseases of aquatic organisms, 27(2), pp.131-139.

Corteel, M., Lima, P.D.D.R., José, J., Tuan, V.V., Khuong, T.V., Wille, M., Alday-Sanz, V., Pensaert, M., Sorgeloos, P. and Nauwynck, H., 2012. Susceptibility of juvenile Macrobrachium rosenbergii to different doses of high and low virulence strains of white spot syndrome virus (WSSV). Diseases of aquatic organisms, 100(3), pp.211-218.

Di Leonardo, V.A., Bonnichon, V., Roch, P., Parrinello, N. and Bonami, J.R., 2005. Comparative WSSV infection routes in the shrimp genera Marsupenaeus and Palaemon. Journal of fish diseases, 28(9), pp.565-569.

Durand, S.V. and Lightner, D.V., 2002. Quantitative real time PCR for the measurement of white spot syndrome virus in shrimp. Journal of Fish Diseases, 25(7), pp.381-389.

Escobedo-Bonilla, C.M., Wille, M., Sanz, V.A., Sorgeloos, P., Pensaert, M.B. and Nauwynck, H.J., 2007. Pathogenesis of a Thai strain of white spot syndrome virus (WSSV) in juvenile, specific pathogen-free Litopenaeus vannamei. Diseases of aquatic organisms, 74, 85-94

Jeswin, J., Anju, A., Thomas, P.C., Paulton, M.P. and Vijayan, K.K., 2015. Analysis of viral load between different tissues and rate of progression of white spot syndrome virus (WSSV) in Penaeus monodon. Aquaculture research, 46(8), pp.2003-2012.
Lightner, D.V., 2012. Global transboundry disease politics: The OIE perspective. Journal of invertebrate pathology, 110(2), pp.184-187.

Shi, H., Yan, X., Ruan, L. and Xu, X., 2012. A novel JNK from Litopenaeus vannamei involved in white spot syndrome virus infection. Developmental \& Comparative Immunology, 37(3-4), pp.421-428.

Stentiford, G.D., Neil, D.M., Peeler, E.J., Shields, J.D., Small, H.J., Flegel, T.W., Vlak, J.M., Jones, B., Morado, F., Moss, S. and Lotz, J., 2012. Disease will limit future food supply from the global crustacean fishery and aquaculture sectors. Journal of invertebrate pathology, 110(2), pp.141-157.

Verbruggen, B., Bickley, L.K., van Aerle, R., Bateman, K.S., Stentiford, G.D., Santos, E.M. and Tyler, C.R., 2016. Molecular mechanisms of white spot syndrome virus infection and perspectives on treatments. Viruses, 8(1), p.23.

Walker, P.J. and Mohan, C.V., 2009. Viral disease emergence in shrimp aquaculture: origins, impact and the effectiveness of health management strategies. Reviews in Aquaculture, 1(2), pp.125-154.

Yuan, F.H., Chen, Y.G., Zhang, Z.Z., Yue, H.T., Bi, H.T., Yuan, K., Weng, S.P., He, J.G. and Chen, Y.H., 2016. Down-regulation apoptosis signal-regulating kinase 1 gene reduced the Litopenaeus vannamei hemocyte apoptosis in WSSV infection. Fish \& shellfish immunology, 50, pp.109-116.

Zhao, C., Fu, H., Sun, S., Qiao, H., Zhang, W., Jin, S., Jiang, S., Xiong, Y. and Gong, Y., 2017. Experimental inoculation of oriental river prawn Macrobrachium nipponense with white spot syndrome virus (WSSV). Diseases of aquatic organisms, 126(2), pp.125-134.

\section{How to cite this article:}

Jeena K., Rahul Krishnan, K. U. Shyam, P. Gireesh Babu, W. S. Lakra, C. S. Purushothaman and Pani Prasad K. 2018. Dynamics of Infection in Selected Tissues of White Spot Syndrome Virus-Infected Litopenaeus vannamei. Int.J.Curr.Microbiol.App.Sci. 7(06): 3003-3008. doi: https://doi.org/10.20546/ijcmas.2018.706.353 